\title{
EVOLUTIONARY NATURALISM AND THE MIND-BODY PROBLEM.*
}

$O$ problem is more crucial for a naturalistic view of
the world than the mind-body problem. Here the physical world and mind somehow unite in a functional whole. Separate them as much as we will in our abstract thoughts, they refuse to remain separated in reality.

The way in which the mind-body problem has been conceived-both as regards the terms and as regards their supposed relations-has been due to ideas of a very general nature. It has reflected assumptions which for various reasons - to be understood only historically-have dominated the thought of the day. The traditional attitudes taken toward this problem are speculative and bound up with the general bewilderment in philosophy. On the whole, it was assumed that mind and body are existentially separate, and so the question came to be that of their causal relation or lack of causal relation.

The task of the present chapter will, therefore, be twofold. We must show the false premises upon which the old dualisms were founded, and we must render intellectually conceivable the functional presence of consciousness in the human organism. We must try to do as clearly as the difficult subject permits what materialistic naturalism

"[Like the articles "The Status of the Categories" and "Space and Time" in the April and July numbers of The Monist, the following is taken from a volume on Evolutionary Naturalism which we expect to publish next spring. -ED.] 
of the older type with its intuitionalistic idea of knowledge and its lack of appreciation of organization and novelty could not accomplish.

The view we shall adopt in our approach is that the mind-body problem, not being specific in the experimental sense and being entangled with all sorts of conflicting assumptions, is largely a philosophical venture. What is required is a clear analysis of the terms and of our knowledge of them. A point of view must be achieved from which the well-grounded generalizations of the physical and the mental sciences can be harmonized. It is obvious that such an achievement is impossible without an analysis of fundamental categories. The greater part of this work has already been accomplished. Our present task is to apply these results to the mind-body problem.

Such, if I mistake not, is the logical situation of the mind-body problem and the reason why philosophers must have a peculiar interest in it. But if philosophy is to be a coordinating science resting upon, and cooperative with, the special sciences, its interpretation of the problem must reflect the march of events in these sciences. It cannot isolate itself in the old romantic fashion and trust solely to the powers of dialectical speculation. Its hypotheses must spring from the pressure of the general scientific movement and reflect in their growth the point of view and the fertile suggestion which such pressure gives to the creative imagination. But, added to this, philosophy must contribute a clear analysis of the actual content of experience and a sharpened notion of cognition.

Traditional Solutions. - The traditional solutions of the mind-body problem have a metaphysical parentage which goes back to the early days of modern philosophy. Dualistic theories have a Cartesian flavor, while monistic speculations are tinged with Spinoza's postulation of a funda- 
mental substance with two knowable attributes. One of the perplexing features of the modern forms of dualism and monism is their vagueness in regard to substance. It is often difficult to determine just how far they continue to retain the Cartesian or the Spinozistic ontology. This very fact shows their weakness; they are compromises between tradition and empirical facts.

Parallelism of this metaphysical temper would maintain that mind is a thinking substance, that is, a self-subsistent entity whose essence is thought. Body, on the other hand, is a substance whose essence is extension. Being, by definition, absolutely different in nature, their relations become meager and practically unthinkable. It will be remembered that Descartes admitted interaction, although he could not really explain it or conceive it satisfactorily.

Spinozistic monism has never been satisfactory because it implies a notion of substance largely outgrown. Substance as the self-existent is combined with a logical notion of substance as the subject of attributes. But the union in this transcendent substance of the attributes, thought and extension, seems verbal as soon as this logical notion of substance is rejected. Valuable as a development of Cartesianism, it has insuperable objections to face. ${ }^{1}$

Like metaphysical parallelism, interactionism has usually been a dualistic theory maintaining that mind (or soul) and body are distinct existences of alien natures which yet act upon each other in perception and volition. There is hardly less of the old dualistic tradition in interactionism than in parallelism. The mind or soul which is said to act upon the brain is regarded as a substantial entity of a unique sort. It is, of course, this assumption which it has in common with metaphysical parallelism that the evolutionary naturalist will not grant. May not the mind be a

1 See Stumpf, Leib und Seele, p. 16. The objections summarized by McDougall are worth close consideration. Universal parallelism does not have a factual foundation. 
term for the integrative action of the nervous system? And may not consciousness be connected up with such action in an intelligible way?

We must distinguish the dualistic type of interactionism, which postulates two kinds of existences, from the empirical, psychological form. Often the psychological interactionist is simply championing the efficacy of consciousness and has no clear idea of what, exactly, the physical world is or of the relation between it and consciousness.

When we speak of interactionism, however, we shall mean any position that assumes a metaphysical dualism and still asserts a causal relation between the kinds of reality. Such interactionism has kinship with the soultheory, and its advocates are usually, if not always, animists and vitalists. Thus a belief in the efficacy of consciousness is not enough to label a thinker an interactionist.

The older theory of the soul made it an immaterial substance underlying consciousness. When Locke made this immaterial substance a permanent unknowable, he gave the soul a shrewd blow; especially so because of his empirical idea of personality and personal identity. Contemporary advocates of the soul-theory for this reason fight shy of the term substance. They do not believe in a transcendent, unchanging substance. What they do affirm is the need for something other than the body. As existential theories, parallelism and interactionism agree in this affirmation. And it is, of course, what we are going to attack. Thus interactionism is just a more daring dualism than parallelism. It asserts a causal relation, while parallelism refuses to do so.

Let us glance at some of the difficulties confronting metaphysical interactionism. Physical things are always spatially related, and causality in science implies this background or context. But the soul acts into space rather than in space. This is the fundamental objection, but there 
are others which develop it. First, does not interactionism imply a denial of the constancy of energy? The brainevent acts upon the soul, and the soul reacts; and so the physical system ceases to be self-contained. Secondly, the soul either acts without the need of energy or it possesses its own peculiar and spiritual kind. And yet bodily nourishment affects the activity of the mind. So does sickness. Who does not feel the essential truth of Gissing's reflections: "The very I, it is plain, consists but with a balance of my physical elements, which we call health. Even in the light beginnings of my headache, I was already not myself ; my thoughts followed no normal course, and I was aware of the abnormality. A few hours later, I was but a walking disease; my mind-if one could use the wordhad become a barrel-organ, grinding in endless repetition a bar or two of idle music." Does not the dualism seem to be an illusion due to some weakness in approach and formulation, to be confusedly verbal rather than real? Thirdly, how does the soul know when and where to act upon the brain to produce desired results? It would seem necessary to assume unconscious knowledge of the minute structure of the brain, and that by something other than the brain. We are thrown into the clutches of the mysterious with a vengeance. Even Bergson with his instrumentalist theory is forced to hold that brain and spirit overlap in pure perception. Fourthly, whence comes the soul? Why does it accompany organisms? Does it assist in the synthesis of these organisms, as vitalism suggests? Do souls have their embryology and development? Why are souls and bodies as fittingly connected as if both had the same heredity? Fifthly, by what right is it assumed that the brain cannot perform those functions assigned to the soul as an imperceptible thing? May it not be that the soul-body dualism of tradition is at work in this conviction that there must be two things instead of one? 
The modern exponent of interactionism is practically always an animist and a vitalist. Thus McDougall writes: "It is just because we have found that mental and vital processes cannot be completely described and explained in terms of mechanism that we are compelled to believe in the cooperation of some non-mechanical, teleological factor, and to adopt the hypothesis of the soul." ${ }^{32}$ Let us bear this reason in mind. Evolutionary naturalism does not believe that the higher levels of nature are purely mechanical; it accepts critical points with resultant new properties. The struggle between animism and naturalism centers here.

But there are some thinkers who frankly identify the soul with the self as a unitary system of experiences and refuse to admit the necessity for a thing with capacities. Yet the difficulties confronting this purely experiential conception of the soul are many. Is the soul intermittent? Can it cease to be, as in sound sleep, and be reborn identical with what it was? What is the basis of retentiveness? Yet we must again admit that this empirical analysis of the soul must be recognized by naturalism. To cover the facts is one of the basic requirements of an adequate naturalism. There is much to suggest that empiricists who are dualists are so as the result of a false epistemology and a resultant underestimation of the living organism. While animists are firm believers in the mechanical theory of the physical world, empirical interpreters of the soul are apt to be naive realists also. ${ }^{3}$

\section{The Empirical Difference between Interactionism and} Parallelism.-When we shake our thoughts loose from the older substance-theories and ask ourselves just what the empirical difference between interactionism and parallelism is when these are taken as working hypotheses, we find

2 McDougall, Body and Mind, p. 365.

${ }^{3}$ I am referring to Laird's excellent book entitled Problems of the Self. 
that the main divergence concerns the efficacy of consciousness.

Interactionism intercalates mental states between the incoming stimulus and the outgoing motor discharge and so breaks the continuity of the physical series. Strictly speaking, this intercalation is in the brain, so that the mental state, be it image or meaning, comes between two brain-events. To those who object that an image can have no causal grip on the brain of the external or transeunt sort here implied, it is answered that transeunt causality is a mystery which must be accepted.

I have already offered a number of objections to interactionism. To these I would add the suggestion that mental states are unthinkable apart from the body of whose functions they seem to be an inseparable expression. Cannot the mental state be given a setting in the brain of such a character that its efficacy does not involve a discontinuity and action from outside? Interactionism would appear to champion a truth, but to do so clumsily just because it is dualistic.

Empirical parallelism differs from interactionism on two points. First, it asserts a temporal correlation between mental state and brain-event. Every mental state has a correspondent brain-event. Interactionism, on the contrary, regards its intercalated mental states as literally self-sufficient. There is only one mixed series instead of two parallel series. Second, parallelism holds to the inefficacy of consciousness so far as cortical events are concerned. The two series do not interact. As I have already suggested, parallelism would appear to champion a truth in so far as the first point is concerned-though this correlation cannot be proved in any direct fashion.

The naturalistic view which I am going to develop has as yet no very good name. It holds to the effective presence of consciousness as a natural ingredient of function- 
ing cortical systems. In one place I have called it the unity-theory, "but that term expresses only one side of the position, viz., the denial of dualism. From another angle, it can be called a critical development of the double-aspect theory. To the student of mind-body literature, one thing is plain: we ought to shake ourselves loose from conventional solutions; they contain too many assumptions.

Why has Mind been Excluded from the Organism?Until very recently, dualistic theories have been in the ascendent. The reasons for this exclusion of mind are worth study.

The first reason may be called epistemological. The physical world is the object of scientific knowledge, while consciousness is the seat and means of knowledge about it. This contrast is readily taken to be an ontological contrast. I presume that this interpretation is made easier by the tendency to believe that the very stuff of the physical world is revealed in knowledge of the physical realm. Scientific realism takes the form of an intellectual intuition of things. Thus a naive epistemology is the inevitable generator of a naive dualism. Two realms seem spread out before the gaze of man: the realm of consciousness and the realm of physical things; and it is so easily assumed that they are given in a comparable way. Hence, to say that body has anything in common with consciousness is like saying that black is white. The difference is held to be almost inspectional in type.

The dualism suggested in this way is supplemented by a logical motive. The categories which develop in our knowledge about the physical world are not identical in many respects with those which characterize consciousness. I presume that the one striking exception generally admitted is time. Hence, the two general objects of thought

- The Essentials of Philosophy, Ch. 22. 
cannot be identical. Consciousness is not simply the physical world, and the physical world is not simply consciousness. It is natural, then, for the logical motive which shows a disparity to be interpreted along the lines of prepossessions awakened by the epistemological motive. It is forgotten that there are other possible existential relations besides simple identity.

The third motive may be called methodological. There has been a working dualism growing out of the data of the sciences. This has meant an ignoring of questions of the nature of consciousness as not relevant to the content of knowledge. The scientist's cognitive interest was in the physical world and not in consciousness; and in the world so known through the data of observation he could find nothing which reminded him of consciousness as he understood that term. The point is a somewhat subtle one and to some extent involves the first motive. Consciousness was often conceived as something which could be perceived if it were in the physical world. By naive realists-or at least intuitionalists of a conceptual sort-the physical world was thought of as something directly observable; and the tendency was to assume that consciousness, also, was something of like possibility; why could not consciousness be perceived if it were there? Need I point out that the critical realist affirms that this whole argument has no validity? The physical world cannot be intuited, for what we perceive is the content of perception; and the recognition of this situation makes it absurd to seek to perceive consciousness as an object in the sense that the physical existent was supposedly perceived. Even were consciousness in the physical existent, it could not be perceived in the naive sense, for no part of the existent is intuited in this sense.

But still another methodological motive was at work in the science of the past. Let me put the situation in the 
following way. Most of us, I imagine, would be inclined to say that there is neither mind nor consciousness in inorganic nature. But science was for many years an investigation of inorganic masses. Only lately have the natural sciences gained a fair measure of autonomy and self-confidence enough to suggest new categories. And if the dominant sciences were physical and chemical and dealt below the level of the organism, it is not strange that the category of mind did not appear as involved in the data and their necessary interpretation. The absence of mind as a category is just what we should expect. And since evolution was not taken seriously, the conclusion drawn was that all phases of nature could be understood without the idea of mind. As we shall later see, behaviorism is unwittingly raising the question whether this be so.

A sort of pragmatic dualism grew, then, out of the stage in which science was. Scientists did not feel that mind and consciousness were relevant to the physical world as they knew it. Reinforce this methodological motive by the epistemological and the logical motives discussed above, and the strength of dualism can be appreciated. Yet, on the other hand, it is not without significance that scientists, when speculative, endow matter with the potentiality of life and mind.

New Tendencies in Science.-Within the last two decades, new tendencies of a genuine interest to philosophy have been declaring themselves. These are, (I) a questioning of the adequacy of the laws of mechanics for any field of nature except that of molar masses; (2) the increased recognition of the empirical autonomy of the various sciences; (3) the admission of creative synthesis in nature with accompanying critical points and new properties; (4) the rise of behaviorism as a physical science bringing human conduct into the physical world. 
The implications of these tendencies are fairly obvious, yet it will be some time before they are frankly acknowledged. I want to suggest particularly their bearing upon the idea of continuity. The emphasis previously was upon sameness. New could not come out of the old. Identity precluded differences. But has not this point of view weakened? Genetic continuity seems to us to unite striking differences. We are confronted with pluses. Chemical properties are not the same as physical properties. There is a further plus when we examine the functioning of organic tissues. The older properties are transcended and included. And behaviorism is suggesting that a still more synthetic level is reached in the nervously controlled action of the whole organism.

Evolution seems, therefore, to contain two equally real elements. There is genetic continuity, and there is novelty. Such change is a critical growth within reality. Who has a right to say $a$ priori how great a novelty may arise and so set limits to the possibilities of nature? The extent to which this recognition of evolutionary synthesis has come to the front of late is surprising. It means the frank admission of novelty without an appeal to a superphysical agent. But if we accept the effectiveness of new organization, the rather abstract and dialectical choice between mechanism and vitalism becomes a fallacy of incomplete disjunction. A richer and more empirical approach to biology has opened before us. ${ }^{\text {. }}$

If totality and self-regulation appear as undeniable features of the economy of the organism, they must be recognized as such. This relevance of data to categories and of categories to data is the foundation of the true logic of science. There need be no fear that this empirical auton-

s Though many of Lodge's criticisms of the speculative naturalism of Haeckel are just, his own suggestions are full of a belief in discontinuity of a dualistic type. It would be difficult to connect his view of life with biologica! investigations. See his Life and Matter. 
omy of the sciences will involve disorder. Out of it will come a truer appreciation of the working and genetic possibilities of nature than could be fostered by a rigid and doctrinaire mechanicalism.

Lastly, the development of psychology has led to an increased recognition of its biological foundation. If the behavior of an organism is empirically different from that of an inorganic body, this difference must be admitted. Again, there are obvious differences of capacity in the organic realm. Psychology but confirms the rough conclusions of every-day life when it points out differences of capacity in the animal world.

The Thesis of Evolutionary Naturalism.-The evolutionary naturalist desires to throw off the spell of outgrown categories and points of view and to do justice to new tendencies. The thesis which best accords with this ideal is as follows: The living organism, when properly and adequately conceived, includes consciousness and is the sole source of that differential behavior which distinguishes it from less integrated bodies. Or, to put the thesis from another angle, I shall maintain that the traditional mindbody problem resulted in large measure from false conceptions of both mind and body. There are delicate analyses to be made and false contrasts to be avoided. And for this necessary work an adequate epistemology is absolutely essential. Nevertheless, a sense of the correct lie of the land is fundamental. And I think that I reflect the contemporary drift when $I$ assert that it is a good methodological principle not to assume a dualism unless there is no help for it. In the main, traditional statements sinned against this principle because they started with two substances, or realities. It will be remembered that Locke hesitatingly suggested that one substance might be enough.

My queries will, then, be as follows: Is not the organism 
the object of reference of all the knowledge about it gained by the various observational and experimental sciences, including behaviorism? Do not the contributions of these sciences supplement each other? And is there anything in this tested knowledge which forces us to exclude consciousness from the organism? Finally, what should we mean by mind? Is it the same as consciousness, or is it something bound up with consciousness and manifesting itself in consciousness but yet not merely consciousness? These are not easy questions, but they have the virtue of being fairly specific. If we can answer them in accordance with the drift indicated, the traditional mind-body problem will disappear, to be replaced by such empirical questions as concern the genesis of types of behavior, the varying capacities they reveal, the nature, status and role of consciousness.

Mind as a Physical Category.-Let us disregard the complex and relatively unanalyzed notion of mind usually present in psychologies and systems of philosophy, and see what categories have arisen in connection with the observed behavior of man and the other animals.

The behavior of organisms is interpreted largely as a function of the nervous system. And there are easily distinguished types, or levels, of nervous action and its correlated behavior. Reflex action is stereotyped and seems to involve a particular nervous group, little controlled by the whole nervous economy. Instinctive action is much more complex and mediates many stimuli, together and in succession. It involves the coordination of a series of actions which are in themselves partially reflex; and yet there is more of plasticity and totality in it. Instinctive action shades into intelligent behavior in which there is "learning by the past," selection, and even planning. Such behavior displays intelligence. This ability to meet situations in a 
non-mechanical way through the capacities of the nervous system is the empirical fact which behaviorism stresses. And behaviorism is as much a physical science as is chemistry.

It is becoming customary to speak of intelligent behavior, and to regard mind as a term for the internal processes of the organism which find expression in the overt characteristics of bodily action as examined over a reactive period. Where we have these internal processes we have mind. The recognition of this situation is often expressed by saying that we know what mind does or how mind functions, but that we do not know mind itself. But this form of statement implies that mind is a substantive thing not revealed in its conduct. It also assumes an ideal of knowledge which we have attacked all through these articles. And, besides, is it not truer to the empirical facts, and simpler, to say that in instances of intelligent behavior we know how the organism behaves and that, until the contrary is proved, the conditions of this behavior must be assigned to the organism? Is there anything in the facts which demands the assumption of two objects of knowledge? $\mathrm{My}$ conclusion is that knowledge of what mind does is really knowledge about the organism. The burden of proof rests upon dualism.

If, then, we use mind as a physical category, we should mean by it the nervous processes which find expression in intelligent conduct. The mind is the brain as known in its functioning. It is the brain in its integrative capacities. All the physical sciences give knowledge about the brain, but they do not give the same knowledge. Their propositions are supplementary rather than identical. One of the tasks of evolutionary naturalism is to show how they can be harmonized when once evolution is taken seriously.

The bearing of this approach upon the mind-body problem is readily seen. In so far as mind is a physical category 
growing out of the data of observation, there is no mindbody problem.

Suggestions in Favor of Evolutionary Naturalism.But while there is no mind-body problem in the traditional sense, when this method of approach is adopted, the nature and origin of this non-mechanical behavior becomes itself a subject of inquiry, all the more acute because specific. As long as the abstract, mechanical ideal of explanation, an explanation by reduction, ruled thought, the postulate maintained was that organic behavior could be reduced to a complex series of purely positional, or unintegrated, motions. A physical system was assumed to be nothing but the sum of its parts and their external relations. Organization counted for little. But to-day this postulate has been weakened by the growth of the biological sciences. It is, to say the least: just as possible that a system is more than an external sum of parts, that it is an organization in which the whole exerts a control over the parts, that the resultant is a function of the system.

But if these new tendencies are accepted, their implications must be worked out. The implication which I have constantly stressed is the forced admission of levels of cansality in nature expressive of organization or creative synthesis. In other words, the empirical data force the thinker to construct categories corresponding to them, categories continuous with the old, and yet obviously striking a new note. Thus the mental level in nature is the level of intelligent behavior - of which, of course, there are degrees. Mental processes are brain-processes, and these control and express themselves in behavior.

Added knowledge about Organisms.-The behavior of individuals must be enlarged to include gesture, facial expression and language. Such data of observation are pe- 
culiar because they are interpreted by the observer as symbols of inner states of consciousness to which he cannot otherwise penetrate. This act of interpretation is instinctive in its foundation and carefully cultivated because of its value. We should note, further, that there is an agreement between the overt behavior of the organism and the meanings of these symbols of expression and language. A says that he is going to the Campus, and I find that his body moves in that direction.

Overt behavior consists of the movement of the whole body or of a part in response to a stimulus or a situation. This second kind of behavior is not a physical adaptation like an animal's serial actions, but is social in its intention. It is essentially a communication. Let us see what it communicates. But first let us note that these words and gestures and facial expressions are symbols to us because we know, or think that we know, what they mean. Their meaning is, therefore, a part of the objective datum. A shake of the head means the feeling and idea we have when we say no.

The second series of behavior-data offers us a knowledge of the mental states of the individual who is communicating with us. Note that I say knowledge and not participation in. What we do is sympathetically to reproduce the mental state of our communicant, that is, we produce the meaning of the symbol. In the case of gesture and expression, this production is a trained reaction in which we sense an identity between our experience and that of the other person. We may call this a sufficient identity of content-with which alone we are concerned. In the case of words, we understand his statements and say that we know what he means or feels.

This added knowledge of the organism gives us an increased grip on mind. We said that for the physical sciences mind as a category covered the character of the 
cerebral processes which control and find their expression in overt behavior. But now in these data of behavior which are symbols we gain knowledge of ideas and feelings which, combined as desires and plans, precede the behavior as apparent control of it. We are led into a deeper knowledge of mind. But a knowledge which raises perplexing questions.

The Epistemological Situation.-We must be careful to keep the epistemological situation clear if we are to thread our way through the coming difficulties. Let it be remembered, first of all, that all knowledge arises and exists only in the consciousness of individuals. The other point to remember is that there are at least two general kinds of knowledge: that which terminates upon data and is their interpretation by means of concepts, and that which uses interpreted data as material for knowledge about objects outside of the knowing consciousness. This latter kind of knowledge, which we have frequently called referred knowledge, divides into two sorts: ( I) information about things of the type founded on the characters of sensedata, and (2) knowledge of the contents of other minds through the mediation of symbols.

In the case of another person, the knowledge gained in the various sciences is information about the organism of the sort mediated by the character and relations of sensedata intelligently handled and interpreted. This other person is an organism independent of the knowing individual; while the sense-data, interpreting concepts and propositions, are a part of the consciousness of the knower. We have seen that modern knowledge of the brain is beginning to lead to a realization of its structural and functional complexity. Organization is being recognized as an important feature of particular substances, and surely the organization of the brain is its paramount character. 
Upon the organization of the brain which we call the instincts, there develops a still subtler and more plastic organization of habit and idea. Something of this sort is the information we possess of the functional texture of the brain.

Knowledge of the content of another mind is assertion of identity of content under the guidance of symbols. My feeling is enough like yours to be identified with it contentually. When you look pleased, I read into you vaguely my experience of pleasure. When you use certain words, I interpret you as having the same meanings in your mind that they suggest to me. How constant and unremitting our testing of this assertion of identity is! Ultimately, I presume, it rests upon correlation of behavior and meanings. If you say one thing and do another, you are either a liar or these symbols do not have the same meaning for us both.

We possess, accordingly, two kinds of knowledge about another's mind. How can these be harmonized? We admit that assertion of identity of content comes nearest to a literal participation in the reality known. Information-about, as critical realism insists, does not involve the presence of the physical reality in consciousness; and knowledge of content does not require the givenness in the knower's consciousness of the mental state known.

Another point. The situation in regard to another is es. sentially the same as that in regard to our own self, in all that concerns the mind-body problem. We know that another has a stream of consciousness; we experience our own stream of consciousness. We have information about his organism and essentially the same information about our own.

The Relation between Consciousness and Brain.-Mind has been an ambiguous term somehow felt to cover cere- 
bral capacities, subjective operations and the changing content of consciousness; and as long as consciousness was thought of as alien to the organism qua physical thing, mental operations tended to be loosened from the body in sympathy with it. Not until consciousness is seen to be included in the brain will the term mind cease to be ambiguous and the age-old problem vanish in the more adequate conception of the living organism.

What, then, is the relation of consciousness to the brain? And how can we insert it into those cerebral processes which control intelligent behavior? Can mind as a category of physical science coalesce with mind as an appreciation of what takes place in consciousness-recollection, reasoning, valuing, planning-into a deeper knowledge about the content and operations of the brain?

There are, then, for the critical realist cortical processes which control and find expression in behavior; and there are conscious processes which apparently have a similar relation to behavior. We can only have information about the cortical processes, while we can either experience (in the case of ourselves) or know (in the case of others) conscious processes. How shall we conceive the relation between these two?

Empirical parallelism stresses what may be called a temporal correlation. The events in one series are temporally correlated with the events in the other series. Historically, this empirical correlation has passed through two stages and is just entering upon a third. The first stage may be called psychophysical correlation. This formulation was characteristic of the time when the brain was dogmatically conceived as a kinetic mechanism. The correlation could be only temporal because the two series did not have even a common form. What in consciousness could correspond with an atomic movement? The second stage may be designated psychophysiological correlation. 
It stressed the temporal ordering of mental states with complex physiological processes. It was a psychochemical correlation in theory.

The third stage is just being entered upon. It is difficult to select a term descriptive of it. What is emphasized is the fact that the brain has functional "sets" and that a pulse of consciousness should be correlated with such a "set." What it stresses is the natural correlation of functional unities on both sides.

Thus temporal correlation is being supplemented by what may be called both formal and functional correspondence. There is an agreement of method between the conscious processes and the cerebral processes. Corresponding to association is the connection of neuronic groups; corresponding to the compresence of various sorts of sense-data is the cofunctioning of various subsystems; corresponding to meanings is some sort of process of summation. These correspondences have not been traced in detail because of the almost insurmountable difficulties on the technical side. Let our ignorance be admitted. Yet it holds even more fully for the older kinetic interpretation; and such knowledge as we possess indicates a far-reaching agreement in the principles characteristic of the two objects of study. The two domains harmonize in a way that suggests that they cannot be external to each other.

If these conclusions be admitted, the evident next step is to ask ourselves whether there is any sufficient reason why the flow of consciousness cannot arise literally in the brain as a part of its functioning. I have elsewhere sought to canvas the customary reasons for the exclusion of consciousness, and need here only repeat my conviction that they are founded upon misconceptions. ${ }^{\circ}$ Critical realism undermines natural dualism with its vague assumption that we possess an intuition of the very stuff of the phys-

- Cf. Critical Realism, Ch. 9. 
ical world that makes the presence of consciousness almost a logical contradiction. Of course, we cannot pass from our information about the physical world in any of its parts to an inference of any conscious content. But why should we expect such an impossible transition? It is an epistemological absurdity.

We have information about the brain, but no apprehension of the stuff of the brain, that is, no intuition of what physically is, no complete vision of its contents. Consciousness is a term for data which are open to inspection and analysis. Of it, alone, do we have a revelatory acquaintance. It follows that the setting of consciousness in the brain cannot be given. In other words, by the very nature of the case, we are precluded from witnessing the ontological linkage of consciousness with the being of the cerebral processes. Picture-thinking will not help us and is apt to lead us astray into patent absurdities. The situation is unique.

The Nature and Function of Consciousness.-Interactionism of the traditional type makes of consciousness a self-existent substance which externally acts upon the neural processes. Descartes's crude theory has given way to a mystical, because unintelligible, idea that consciousness affects the neurones at their synapses in the way of heightening or lowering resistance to the passage of a nervous current. But such an action in any plan must needs be very complicated. It would be like the playing of very many notes at the same time on the keyboard of a piano. It would seem much more likely that the cortical pattern in its entirety is a growth which is changed here and there under demand. It is more like the synthesis of modes of functioning, genetically developed, than like an action from outside.

The efficacy of consciousness must be relative to its 
nature. There are those who can conceive of consciousness as having efficacy only if it is a form of energy. But energy is only a term for certain quantities in our knowledgc about the physical world. I think that there is much plausibility in speaking about mental energy as a term descriptive of mental capacity. Thus those whose personality tends to dissociate are said to lack mental energy. But are we in these cases thinking about consciousness alone, or about it in its setting and conditions? I am persuaded that the latter is the case. Consciousness is inseparable from energy changes, but I do not believe that we are speaking critically when we say that consciousness is a form of energy.

If consciousness is not a form of energy but just what it is given as, we must seek suggestions as to the character of its efficacy by a study of its conditions and its apparent function. Here we have an instance of real or ontological causality; we seem to be on the inside of nature as participants. Moreover, if our appreciation of the new tendencies in science is correct, consciousness is the correlate of cortical systems and not of particular cells as units. It has too readily been assumed that there was only question of efficacy of an impact type. But consciousness does not reveal the slightest basis for impact in its content. It is not a physical thing and cannot perform the operations of a physical thing.

What does experience suggest the probable function of consciousness to be? If this function accords with its na-ture, we should be on the track of the mode of efficacy of consciousness. To answer this question we might study the process of motor learning or reflect upon cases of action after deliberation. In the first type of case, it seems clear that some sort of ordered fusion is facilitated by conscious-

7 It is better to speak of mental energy since energy is a category of physical science. 
ness. It plays about growing points of integration. It seems to aid the growth of a complex system in which the parts touch one another off. We would appear to be to a slight extent on the inside of a process of synthesis. The organism on its nervous side functions as a whole in adjustmental reactions to its stimuli. Such reactions are by their very nature synthetic, and not physiological in a discrete sense. Percepts are peculiar expressions of the reaction and, by that very fact, cues which can represent it. I judge that the sensory content has the individuality of the system in which it has its roots. The one is as singular and specific as the other. But learning involves attention, and attention implies an organic interest and a larger system than the nervous basis of the sensory content. It is in and through the attention-system that conscious learning develops. And if this system has its conscious aspect or level-its focal rise into consciousness-it is not unlikely that its process is furthered thereby.

In action after deliberation, we have a conscious process of active selection in the light of ideas of consequences, all being guided by purpose and mood. And our decision certainly takes the form of a plan which appears to guide action and assuredly corresponds to our behavior. Hence our natural belief is that this conscious process counts for something; that, without it, intelligent behavior would be impossible. Are we justified in this belief? If consciousness is an internal complex of contents, sensory and affective, which are determinate reflections of the set of functional systems in the cortex under the play of intra-andextra-organic stimuli, it may serve as a guidance or it may simply reveal the course of cortical processes. The one view is in sympathy with what interactionism has desired to defend-although blunderingly; the other view is analogous to epiphenomenalism.

In this dilemma, I accept the position that consciousness 
is efficacious, that it has a function to perform. It seems to me to be a natural ingredient whose function is to aid in the solution of problems by the cues it affords. Iiterally, it assists the brain to meet new situations. The brain is coordinative, and consciousness is at once the expression and the instrument of that coordination. Planned action involves a changing system of great complexity in which there is an ordering of elements to one another. Consciousness does not link molecules, for that would be to materialize consciousness, to make a physical thing out of it. To put the suggestion bluntly, it is just because consciousness is not itself a physical substance, not a substance at all in fact, that it can be the focus of functional totality and guidance. Thus, out of an apparent dualism, we can achieve the thought of a more adequate monism which does not ignore differentiation. It is absurd to deny that consciousness is as we experience it. The fault with the traditional dualism was that it made consciousness into a substance coordinate with, and external to, physical substance. It is a unique variant expressive of the shifting unity of a highly organized system. It is, as it were, the eye of that system. Critical integrations must be intelligent if they are to meet the requirements of the organism. But we cannot understand their intelligence unless intelligence is actually at work within them as a part of their nature. In thinking, planning and desiring-in all those conscious processes which we call activities-we are on the inside of the brain and at its focal level of operation. Here objective and subjective activity are identical.

Advantages of this Theory.-If consciousness is at once the conditioned expression of the cortex and the instrument through which operations such as discrimination and anticipation are carried on, we can readily meet the traditional objections to the efficacy of consciousness. 
In the first place, energy and its measurement applies to the whole cortical system. It is knowledge about the brain. Interactionism at least tends to make consciousness a substantial system external to the cortex and, for that reason, is confronted with the principles of science which assert that the physical world is a closed universe.

In the next place, our view takes the sensori-motor process as a unit and holds that the cortical integration of which consciousness is an element is always genetically continuous with a motor pattern of the brain. In other words, cortical integrations arise in one system with motor tracts. This means that ideas are from birth immersed in neural processes which have motor extensions. Ideas and motor tendencies are always on the same circuit. $A$ dominant idea means a dominant cortical system, and such a system possesses its genetically developed roots. Behavior is a growth from instinctive tendencies to action; and it is within such instinctive functioning that conscious action appears. A purpose is, thus, a part of an active system which has its trained expression. Hence, in the brain itself, purposive idea and motor expression are only stages in a continuous neural process. Or, to speak even more exactly, the integration of the idea is at the same time the integration of its motor prolongation. But because only the idea is given to us we are prone to erect a dualism and to ask how the idea by itself-which we forget is an abstraction from its ontological setting-can produce what follows.

We are forced to conclude that the relation of consciousness to the brain is internal and unique. It is a relation which can be understood in some measure only when a correct knowledge about the brain's method of action is added to a proper conception of consciousness. Only then can we, as it were, see consciousness as immersed in, and continuous with, brain-systems in action. Had not M. Berg- 
son been led astray by his sharp dualisms between space and time, spirit and matter, I feel certain that he would have reached such a view as ours. He suggests almost an identity of brain pattern and perception as a basis for the insertion of spirit into matter-from the outside. But for him the higher levels of consciousness cannot have this material matrix. It is impossible ultimately because duration is so different from space. But to us his argument is dialectical and not empirical. The physical world is not merely spatial. His theory of the categories and of the nature of the physical world makes an evolutionary naturalism impossible to him and causes those dualisms which characterize his cosmology. A correct analysis of the categories is thus seen to be fundamental.

Consciousness and Mind.-It has been our admitted purpose to get an adequate idea of mind which will harmonize the information gleaned by behaviorism with that accepted by introspective psychology. We should now be in a position to accomplish this feat.

If mind is a term for the nervous processes which find expression in the differential behavior of the organism, then objective psychology gains valid knowledge about the capacities, tendencies and general mode of operation of mind.

But if consciousness is at once the expression and guide of mind, changes in contents should indicate the activity of mind. For instance, an act of comparison is a process in which contents are correlated and brought synthetically together; and such an act is the function of some interest. We can find no creative agency in the contents of consciousness as such, but we do feel that they are present in and aid a genuine activity of the personality. They are elements in those selective and dynamic complexes which we call instincts and desires. The brain as mind is a more or 
less integrated system of propensities and interests which respond to the situation in which the individual is placed. And such interests must not be thought of as physiological in any sense that excludes discriminative appreciation. They are neurological systems whose urgencies are inclusive of mental contents.

Consciousness must be connected psychophysically with neural processes of some reach. Attention, itself, can be understood only as a forward movement or passage in which the cerebral activity makes its path. What we must seek to do is to deepen our conception of the brain as at once activity and content. It is sensori-motor, ideo-motor; it is a stream of tendencies lit up by consciousness. The brain is synthetic because it is active. It is a more or less unitary process controlled by the neuronic system which is functionally uppermost. It is hard to describe what the reflective mind feels, that personality is like the deep heaving sea with its currents and counter-currents. It is the pressure of this complex, internal immensity that we call interest.

Our conclusion is that consciousness is a part of mind but by no means the whole of mind. It is too evanescent and passive, too little self-explanatory, to be so considered. It is relative to an organism and to that organism's activities.

If the arguments of this chapter stand firm, we have established the thesis that the living organism, when properly and adequately conceived, includes consciousness as a characteristic, internal feature of the functioning, neuronic system. It is a quality of a novel whole, and is as novel as the synthetic whole of which it is an expression. I have frequently called it a variant to bring out its existential correlation with a complex process. The field of experience of any one time is a psychical structure which corresponds to the activity of the organism. This correspond- 
ence we have tried to explain in connection with perception as a neurally mediated activity.

When I conclude that any psychical fact is a quality of a nervous complex when functioning synthetically, I do not, of course, use quality in the sense of naive realism. The brain is not red when the psychical entity, red, arises in it. The use of psychical entities as the material of knowledge, while the object of perception is confused with the content of perception, gives rise to this misinterpretation of the psychical content. This problem involves the category of quality which we have discussed in an earlier chapter.

Psychical entities are not substances, but rather peculiar characteristics of novel wholes and inseparable from them. As soon as such psychical entities are thought of as selfsufficient things, dualism breaks out and they are extruded from the brain by our thought. As soon as they are conceived as more than contents, as more than they themselves reveal, as soon as they are given by themselves power to do things, they become to the deceived thinker non-physical and alien to physical reality. And it is very difficult for one to avoid these errors unless he is master of an adequate epistemology which has clearly seen the fallacy of naive realism.

Psychical entities are, then, contents which arise in the synthetic brain, and they are aids in the discrimination and correlation of objects. In terms of such contents acts of memory and anticipation clothe themselves, all this proceeding in the brain as a natural part of its adjustmental function. The brain has been underestimated in the past in behalf of a hypothetical reality postulated to perform functions rather dogmatically asserted to be impossible to a physical organ however delicate its structure. In contrast, we have argued that the brain is rightly conceived only when we supplement all the knowledge gained by the 
physical sciences about it by all that the mental sciences can teach. It is literally the brain-mind, the home of consciousness and of mental capacities.

Panpsychism and Materialism are Extremes. - The evolutionary naturalist desires to combine the total information he can gather about the human organism. He knows himself to be an evolved substance of tremendous complexity whose material is that which he consumes each day in food and drink. He thinks, acts, adjusts himself to complex situations, ministers to his body, experiences fatigue, has sicknesses, etc. That is the kind of a thing he is. $\mathrm{He}$ is all of these cooperative functions at one and the same time. And yet the conscious self sits quite obviously in the watch-tower of the brain to guide the organism's behavior.

Materialism builds its outlook upon the conclusions of the physical sciences, and, naively taking this knowledge to be exhaustive of the organism, can find no room or function for consciousness. We have tried to correct this mistake by pointing out that in consciousness we are on the inside of the organism, or, to speak more correctly, are a literal part of the organism. We have also found that mental contents function in a guiding way in those operations of discrimination and correlation which the brain performs. Our conception of the brain has wonderfully enlarged as a consequence.

Panpsychism, on the other hand, starts from consciousness as something we are sure of and seeks to conceive it as capable of fitting the demands of the physical sciences. Much of past panpsychism was idealistic in its epistemological setting and so lightened its task. But for us panpsychism must make plausible the structure of the brain and the massive properties and relations of the physical world. Mental contents as I am aware of them or as I introspect them seem to me incapable of bearing this bur- 
den. The contents of consciousness are correlative to neural processes which are not to be found at the inorganic level. They apparently come and go and are not directly conserved; there seems to be nothing more to them than is open to inspection. In short, they are not substantial and dynamic.

But I do not hold that mental entities must be objects of awareness in order to exist. Unconscious consciousness in the sense of psychical entities of which we are not aware appears to me to be no contradiction. Awareness involves a structure within a process of attention. The reason why the idea of unconscious consciousness has so often seemed absurd is the double use of the term consciousness which will be discussed elsewhere. But I do not see any adequate reason to believe that psychical entities of which we are aware differ markedly from those of which we are not aware, and vice versa.

To the panpsychist's objection that he is unable to understand the origin of the psychical from the non-psychical, the natural reply is that the physical world is not the non-psychical in any dialectical sense. If the psychical is novel, it follows that it could not have existed before. Consequently, we have on our hands only the general question of the origin of the novel. But is not the organism with its capacities novel? And why should not such a novel whole be accompanied by novel creations in the tensional adjustments involved? My own mind is not shocked by such a theory. It does not quail before a real, though a conditioned, beginning. Let him who feels otherwise show. how a simple quality like red is the genetic product of something simpler. Frankly, it seems to me that there is novelty of an undeniable sort at every level of experience. Yet I hold that these novelties have their cerebro-mental setting and conditions.

To conclude: the epistemology of materialism is too 
naive, and it founds its interpretation too exclusively upon the inorganic physical sciences. Panpsychism, on the other hand, builds too exclusively upon mental contents because these are the only entities literally given to the conscious self. It has generally been connected with idealism. But when it admits the validity of a critical realism, it has so many difficulties to face in making the psychical the equivalent of the physical world known by science that it ceases to be very plausible.

R. W. Sellars.

UNIVERSITy OF MichigaN. 